\title{
RISET KUANTITATIF DAN KUALITATIF PENGHINDARAN PAJAK: METODE APA YANG TEPAT UNTUK INDONESIA
}

\author{
Ferry Irawan 1)*
}

1)ferry.irawan@pknstan.ac.id, Politeknik Keuangan Negara STAN

\begin{abstract}
Research on tax avoidance has been widely carried out in the last few decades, including in Indonesia. Quantitative research based on secondary data is quite a lot done to determine the determinants of tax avoidance. Meanwhile, only few qualitative research has been done, and generally looks at the possibility of tax avoidance based on the weaknesses that exist in the tax provisions. This study aims to see the right research to be applied in Indonesia. By using a qualitative method with a literature study approach, the author obtains several important findings. First, each research method has advantages and disadvantages. Second, the availability of data for quantitative research with secondary data is very limited. Finally, quantitative and qualitative research are complementary to be applied, especially by the tax authorities.
\end{abstract}

Keywords : quantitative method, qualitative method, tax avoidance

\begin{abstract}
Abstrak
Riset penghindaran pajak telah banyak dilakukan dalam beberapa dekade terakhir termasuk di Indonesia. Penelitian kuantitatif berbasis data sekunder cukup banyak dilakukan untuk mengetahui determinan penghindaran pajak. Sementara itu, penelitian kualitatif tidak terlalu banyak dilakukan, dan pada umumnya melihat kemungkinan penghindaran pajak berdasarkan kelemahan yang ada pada ketentuan perpajakan. Penelitian ini bertujuan untuk melihat riset yang tepat untuk diaplikasikan di Indonesia. Dengan menggunakan metode kualitatif dengan pendekatan studi literatur, penulis mendapatkan beberapa temuan penting. Pertama, setiap metode riset memiliki kelebihan dan kelemahan. Kedua, ketersediaan data untuk riset kuantatitif dengan data sekunder sangat terbatas. Terakhir, riset-riset kuantitatif dan kualitatif bersifat komplementer untuk dapat diaplikasikan khususnya oleh otoritas pajak.
\end{abstract}

Kata Kunci : metode kuantitatif, metode kualitatif, penghindaran pajak

\section{PENDAHULUAN}

Penghindaran pajak (tax avoidance) merupakan kegiatan yang dilakukan oleh sebuah entitas dengan tujuan untuk meminimalisasi pembayaran pajak (Irawan \& Afif, 2020). Penghindaran pajak yang terjadi juga tidak hanya memengaruhi pembayaran pajak namun juga menjadi strategi perusahaan dalam mengelola kas di masa depan (Irawan \& Turwanto, 2020). Studi tentang penghindaran pajak banyak dilakukan oleh peneliti. Penelitian yang dilakukan oleh Arham et al. (2020) menginvestigasi riset-riset penghindaran pajak yang ada di Indonesia. Penelitian ini memetakan 105 riset-riset kuantitatif sejak tahun 1999 sampai dengan 2019. Sementara itu, studi yang dilakukan oleh Wang et al. (2020) dilakukan terhadap riset-riset penghindaran pajak dalam bidang ilmu akuntansi dan keuangan selama sepuluh tahun terakhir. Penelitian terkait penghindaran pajak yang menurut Hanlon \& Heitzman (2010) termasuk bidang riset pajak yang masih baru. Namun demikian, riset ini sangat aktif dan berkembang. Studi penghindaran pajak masih belum membedakan ruang lingkup secara spesifik apakah bersifat domestik atau cross-border.

Sebagian besar riset membahas penghindaran pajak dari perspektif cross-border. Misalnya studi yang dilakukan oleh Meier \& Smith (2020) dan VIcek (2019). Lebih lanjut, penelitian kuantitatif di Indonesia terkait penghindaran pajak dilakukan oleh Ferdiawan \& Firmansyah (2017) Aryotama \& Firmansyah (2020b), Aryotama \& Firmansyah (2020a), Falbo \& Firmansyah (2018), Falbo \& Firmansyah (2021), Firmansyah \& Febriyanto (2018), Irawan \& Turwanto (2020), Firmansyah \& Triastie (2020), Gunawan (2022), Hidayat \& Wijaya (2021), Wijaya \& Rahayu (2021), Irawan et al. (2020), Utami \& Irawan (2022), Prastiwi \& Ratnasari (2019), Winata (2014), Bimo et al. (2019), dan Irawan \& Utama (2021). Studi dengan pendekatan kuantitatif juga dilakukan di negara lain seperti Rabbi \& Almutairi (2021), 
Álvarez-Martínez et al. (2021), Bennedsen \& Zeume (2018), Desai \& Dharmapala (2006), Lejour (2021), Granda (2021), Sebele-Mpofu et al. (2021), Taylor et al. (2015), Graham et al. (2014), Clausing et al. (2020), Chen et al. (2021), Slemrod \& Yitzhaki (2002), Dyreng et al. (2008), Guenther et al. (2017), Amidu et al. ( 2019), Lee (2019) dan Addo et al. (2017).

Sementara itu, studi mengenai penghindaran yang bersifat kualitatif tidak banyak ditemui. Misalnya penelitian yang dilakukan oleh B.M \& Wijaya (2018), Juniawaty (2018) Wijaya \& Arumningtias (2021), Nugroho et al. (2020) dan Wijaya \& Setiawan (2021). Riset kualitatif mengenai penghindaran pajak di luar negeri, antara lain dilakukan oleh Sikka (2015), Hasseldine \& Morris (2013), Finér \& Ylönen (2017), Addison \& Mueller (2016), dan Preuss (2010).

Pada umumnya riset-riset kuantitatif menggunakan proksi dalam variabel penghindaran pajak dengan mengaplikasikan antara lain: tarif pajak efektif (effective tax rate), perbedaan pembukuan berdasarkan standar akuntansi dan ketentuan pajak (book-tax difference), dan pemeriksaan atas SPT wajib pajak (Wang et al., 2020). Riset-riset tersebut juga menggunakan informasi yang ada dalam laporan keuangan untuk memprediksi kemungkinan bahwa perusahaan telah melakukan penghindaran pajak. Di sisi lain, studi kualitatif cenderung tidak menggunakan proksi-proksi tertentu namun lebih menggunakan interpretasi atas ketentuan perpajakan. Misalnya studi terkait kemungkinan pemanfaatan badan hukum dan pemilihan objek pajak terkait ketentuan Peraturan Pemerintah Nomor 23 Tahun 2018 dalam rangka penghindaran pajak dilakukan oleh Wijaya \& Setiawan (2021) dan Wijaya \& Arumningtias (2021).

Penelitian ini bertujuan untuk mengetahui apakah riset dengan metode kuantitatif atau metode kualitatif yang lebih bermanfaat untuk diaplikasikan dalam praktik di lapangan khususnya bagi otoritas pajak di Indonesia. Studi mengenai perbandingan penggunaan metode penelitian dalam bidang penghindaran pajak belum banyak dilakukan. Hal tersebut menjadi kebaruan dari penelitian ini. Selanjutnya, elaborasi lengkap dari penelitian ini diuraikan dalam bagian kajian pustaka, metode, hasil dan pembahasan, serta penutup.

\section{KAJIAN PUSTAKA}

Terdapat tiga prinsip dalam penghindaran pajak yaitu: penundaan pembayaran pajak, memberikan peluang bagi wajib pajak untuk memilih lapisan tarif pajak, dan memanfaatkan perlakuan pajak atas suatu penghasilan (Stiglitz, 1985). Penghindaran pajak tidak mudah untuk diukur. Salah satu alat ukur penghindaran pajak adalah hilangnya penerimaan pajak (Alm, 1988). Praktik penghindaran Pajak dan penggelapan pajak (tax evasion) tidak mudah untuk dibedakan. Penggelapan pajak pada umumnya meningkatkan kemungkinan audit oleh otoritas pajak sementara penghindaran pajak tidak demikian. Hal ini diakibatkan karena penghindaran pajak pada umumnya dianggap legal sementara penggelapan pajak justru bersifat ilegal (degl'Innocenti \& Rablen, 2017). Penghindaran pajak dapat timbul karena adanya peluang yang diberikan oleh sistem adminstrasi perpajakan. Peluang ini diambil oleh wajib pajak dengan pertimbangan penghematan beban usaha. Namun demikian, ada biaya yang harus harus dibayar oleh wajib pajak di kemudian hari. Misalnya, pada saat otoritas pajak melakukan pemeriksaan maka dapat dimungkinkan terdapat penalti yang akan diberikan atas aktivitas penghindaran pajak atau penggelapan pajak (Slemrod \& Yitzhaki, 2002). Penghindaran pajak juga dapat terjadi karena adanya bantuan dari sebagian profesi akuntan publik (Addison \& Mueller, 2016).

Istilah penghindaran pajak dikenal dalam Undang-Undang Nomor 7 Tahun 1984 tentang Pajak Penghasilan sebagaimana telah diubah beberapa kali terakhir dengan UndangUndang Nomor 7 Tahun 2021 tentang Harmonisasi Peraturan Pajak (selanjutnya disebut UU PPh). Selain itu dikenal pula dalam Undang-Undang Nomor 8 Tahun 1983 tentang Pajak Pertambahan Nilai Barang dan Jasa dan Pajak Penjualan atas Barang Mewah sebagaimana telah 
diubah beberapa kali terakhir dengan Undang-Undang Nomor 7 Tahun 2021 tentang Harmonisasi Peraturan Pajak (selanjutnya disebut UU PPN). Penghindaran pajak beberapa kali disebutkan dalam UU PPh khususnya di Pasal 18. Akan tetapi, penyebutan ini muncul dalam penjelasan pasal. Misalnya dalam penjelasan Pasal 18 ayat (2), ayat (3) ayat (3b). Istilah penghindaran pajak ini berkaitan dengan penanaman modal di luar negeri, transaksi dengan pihak berelasi (hubungan istimewa), dan pembelian saham/penyertaan pada perusahaan dalam negeri melalui perusahaan di luar negeri. Selanjutnya, pengaturan terkait untuk mencegah penghindaran pajak diatur dalam Pasal 16C UU PPN. Penjelasan pasal tersebut menyebutkan bahwa kegiatan membangun sendiri dikenakan PPN dalam rangka mencegah terjadinya penghindaran PPN.

Studi terdahulu terkait penghindaran pajak sebagian menggunakan metode kuantitatif. Beberapa variabel umum yang banyak digunakan sebagai determinan penghindaran pajak antara lain thin capitalization, hubungan istimewa, aktivitas luar negeri atau multinationality, manajemen laba dan siklus bisnis atau karakteristik bisnis (Falbo \& Firmansyah, 2018; Aryotama \& Firmansyah, 2020a; Falbo \& Firmansyah, 2021; Ferdiawan \& Firmansyah, 2017; Dwi Laksono \& Firmansyah, 2020; Aryotama \& Firmansyah, 2020b; Nurhandono \& Firmansyah, 2017; Irawan, 2020; Utami \& Irawan, 2022; Irawan et al., 2020; Wijaya \& Rahayu, 2021; Hidayat \& Wijaya, 2021; Wijaya \& Setiawan, 2021). Beberapa studi lain menggunakan variabel di luar komponen laporan keuangan sebagai determinan penghindaran seperti ditunjukkan oleh (Chen et al., 2021; Ferdiawan \& Firmansyah, 2017; Finér \& Ylönen, 2017; Hasan et al., 2021; Hasseldine \& Morris, 2013).

\section{METODE}

Penelitian ini menggunakan metode kualitatif untuk memberikan pemahaman yang lebih dalam atas suatu permasalahan (Cassell \& Symon, 2004). Pendekatan studi literatur digunakan dalam penelitian ini untuk menggali lebih lanjut berbagai teori dan riset-riset terdahulu yang relevan. Literature review memiliki peran untuk membuka berbagai teori yang mendukung argumentasi penelitian (Nakano \& Muniz, 2018). Selain itu, penelitian juga menggunakan ketentuan peraturan perundangan pajak (normatif yuridis) untuk disandingkan dengan literatur agar pembahasan menjadi lebih sistematis dan aplikatif.

\section{HASIL DAN PEMBAHASAN}

\section{Pengukuran-Pengukuran dalam Riset Kuantitatif}

Penelitian-penelitian kuantitatif dengan data sekunder pada umumnya menggunakan komponen laporan keuangan sebagai alat untuk menguji. Selanjutnya, data-data yang telah dibuatkan proksi-nya tersebut diuji menggunakan perangkat lunak olah data. Selanjutnya, temuan penelitian dapat memberikan sebuah rekomendasi pada otoritas pajak untuk lebih memperhatikan variabel-variabel yang menjadi penentu perusahaan untuk melakukan penghindaran pajak. Hal ini terjadi karena hasil pengujian membuktikan hipotesis yang diajukan. Misalnya studi yang dilakukan oleh Wijaya \& Rahayu (2021) mengindikasikan bahwa agresivitas transfer pricing perusahaan berpengaruh terhadap penghindaran pajak. Pengukuran agresivitas transfer pricing diukur dengan indeks dalam komponen laporan keuangan. Sementara itu, penghindaran pajak direpresentasikan dengan fungsi dari jumlah goodwill dan aset takberwujud, kompensasi rugi, dan book-tax difference.

Selanjutnya, studi yang dilakukan oleh Utami \& Irawan (2022) menggunakan proksi tarif pajak efektif, yaitu dengan membagi beban pajak atas laba sebelum pajak untuk mengukur penghindaran pajak. Di sisi lain, proksi yang digunakan untuk mengukur thin capitalization. Salah satu hipotesis penelitian adalah membuktikan apakah thin capitalization berpengaruh terhadap penghindaran pajak. Berikutnya, Studi yang dilakukan oleh Irawan \& Novitasari 
(2021) menggunakan proksi berupa dummy untuk mengukur multinasionalitas, yaitu skor 1 jika perusahaan memiliki afiliasi di luar negeri, dan skor 0 jika tidak. Sedangkan variabel penghindaran pajak diukur dengan GAAP ETR, yaitu dengan membandingkan antara beban pajak atas beban akuntansi sebelum pajak.

Pendekatan kuantitatif dalam studi penghindaran pajak tepat diterapkan dengan objek penelitian berupa perusahaan yang laporan keuangannya dapat diakses. Selain itu, laporan keuangan tersebut telah diaudit oleh akuntan publik untuk memastikan bahwa tidak ada salah saji material dalam pelaporan keuangan tersebut. Hal ini sesuai dengan tugas auditor independen untuk menguji laporan keuangan dan membandingkan dengan standar akuntansi yang berlaku. Di sisi lain, ada kemungkinan perusahaan melakukan penghindaran pajak setelah audit dilakukan oleh auditor eksternal. Hal ini terkonfirmasi oleh studi yang dilakukan oleh Sikka (2015). Hasil penelitian menunjukkan bahwa Kantor Akuntan Publik "Big Four" memiliki akses terhadap pimpinan perusahaan. Selanjutnya, ini dapat menjadi media untuk menawarkan "jasa penghindaran pajak". Selain itu, studi ini juga menjelaskan bahwa "Big Four" memiliki skema baru dalam penghindaran pajak sehingga menjadi salah satu competitive advantage tersendiri dalam menghemat pembayaran pajak.

Kelebihan dari penelitian-penelitian kuantitatif dalam studi penghindaran pajak ini adalah generalisasi atas temuan-temuan penelitian yang diperoleh. Selain itu, penelitian kuantitatif dapat memprediksi berdasarkan data di masa lampau untuk memprediksi kemungkinan di masa depan. Namun, apabila mempertimbangkan jumlah wajib pajak dengan kriteria yang dapat diobservasi nampaknya masih belum memadai. Laporan Tahunan Direktorat Jenderal Pajak Tahun 2020 menunjukkan bahwa jumlah wajib pajak badan sekitar 1,4 Juta. Sementara itu, jumlah wajib pajak orang pribadi lebih kurang 17 juta. Jumlah wajib pajak yang terdaftar di Bursa Efek Indonesia - BEI (laporan keuangan dapat diakses oleh publik) hanya di kisaran 700 perusahaan. Hal ini menjadikan sulit untuk memastikan bahwa hasil studi kuantitatif penghindaran pajak benar-benar tepat untuk diimplementasikan. Selanjutnya, karakteristik perusahaan-perusahaan yang dimiliki publik berbeda dengan yang dimiliki oleh non-publik. Misalnya, tata kelola (corporate governance) perusahaan yang listed pada umumnya lebih baik dibandingkan perusahaan yang non-listed Astrini et al. (2015).

\section{Pengukuran-Pengukuran dalam Riset Kualitatif}

Studi-studi kuantitatif terkait penghindaran pajak berusaha untuk memprediksi perilaku penghindaran pajak melalui pendekatan akuntansi dan keuangan secara umum. Di sisi lain, riset-riset kualitatif menggunakan pendekatan regulasi atau ketentuan pajak. Perencanaan pajak yang dilakukan dengan menganalisis peraturan perundang-undangan yang belaku. Setelah itu, dilakukan simulasi-simulasi tertentu sehingga dapat diperoleh tax shield atau tax benefit bagi wajib pajak. Pengukuran dalam riset kualitatif tidak seperti kuantitatif yang menggunakan proksi tertentu dalam menguji adanya relasi antar variabel. Riset kualitatif penghindaran pajak pada umumnya juga menggunakan perbandingan antara ketentuan satu dengan ketentuan lainnya, antara bentuk usaha satu dengan bentuk usaha lainnya, dan penghasilan/ transaksi satu dengan penghasilan/transaksi lainnya. Berdasarkan perbandingan-perbandingan tersebut, akan dilakukan evaluasi bentuk seperti apa yang dapat menghasilkan pembayaran pajak efisien.

Riset kualitatif pada umumnya tidak dapat digeneralisasi dan memang tidak dimaksudkan untuk hal tersebut. Namun, untuk penghindaran pajak terdapat kemungkinan dijadikan sebagai benchmark atas praktik yang terjadi di lapangan. Hal ini dilatarbelakangi oleh adanya ketentuan pajak yang relatif serupa untuk bentuk-bentuk usaha tertentu. Misalnya pengenaan PPh Pasal 21 atas pegawai tetap dengan penghasilan kena pajak dengan nilai tertentu. Meskipun pegawai tetap tersebut berada di perusahaan yang berbeda lini usahanya, namun pengenaan PPh Pasal 21 akan mengikuti ketentuan yang sama. Butir-butir penghasilan 
yang dapat meningkatkan besarnya pajak terutang dan biaya-biaya yang dapat mengurangkan besarnya pajak terutang memiliki perlakuan yang sama dari perspektif ketentuan perpajakan

Berikut merupakan beberapa elaborasi penelitian kualitatif. Studi yang dilakukan oleh Nugroho et al. (2020) membahas mengenai upaya untuk menghindari pajak dengan cara memecah bidang tanah agar pengenaan PPh Final dari transaksi pengalihan tanah tersebut menjadi lebih kecil. Studi ini mendalami praktik penghindaran pajak dari perspektif qanun atau peraturan daerah yang berlaku. Studi ini menyoroti peran dari pihak Pejabat Pembuat Akta Tanah (PPAT) dalam menjalankan tanggung jawab profesional untuk memastikan bahwa transaksi pengalihan tanah sesuai dengan ketentuan yang berlaku. Studi lainnya. Riset yang dilakukan oleh Wijaya \& Setiawan (2021) dan Wijaya \& Arumningtias (2021) membahas potensi penghindaran pajak yang dapat dilakukan atas pemberlakukan PP 23 Tahun 2018 oleh wajib pajak berbentuk perseroan terbatas. Bentuk penghindaran yang dapat dilakukan antara lain profit shifting. Lebih lanjut, secara teknis wajib pajak akan mendirikan badan usaha baru apabila peredaran bruto mendekati angka $\mathrm{Rp} 4.800 .000 .000$, dan mengalihkan penghasilan ke badan usaha baru tersebut. Dengan demikian, wajib pajak tetap akan dikenakan pajak sesuai tarif yang berlaku di PP 23 Tahun 2018.

Kelebihan riset kualitatif terkait penghindaran pajak adalah pada studi yang mendalam baik melalui elaborasi terhadap ketentuan yang berlaku maupun pendapat dari para narasumber atau informan penelitian untuk memperkuat dugaan peneliti. Riset kualitatif juga dapat memprediksi potensi penghindaran pajak berdasarkan ketentuan yang berlaku meskipun mungkin secara praktik belum dilakukan oleh wajib pajak. Berikutnya, hasil riset ini dapat dijadikan sebagai pertimbangan oleh pembuat kebijakan untuk meminimalisasi penghindaran pajak. Di sisi lain, riset kualitatif ini juga memiliki kelemahan. Misalnya, analis yang dilakukan dalam memprediksi kemungkinan adanya penghindaran pajak menjadi kurang tepat. Hal ini dimungkinkan karena ada variabel atau faktor lainnya yang memotivasi perilaku penghindaran pajak oleh wajib pajak.

\section{Riset yang Tepat untuk Kondisi Indonesia}

Berdasarkan uraian di atas, masing-masing metode riset memiliki kelebihan atau kelemahan masing-masing. Untuk riset di Indonesia sendiri memiliki karakteristik yang mungkin berbeda dengan negara-negara lain. Sebagai contoh: untuk riset-riset kuantitatif dengan menggunakan data sekunder banyak menggunakan observasi berupa laporan keuangan perusahaan-perusahaan yang terdaftar di BEI. Pada umumnya perusahaan-perusahaan tersebut memiliki omset dan aset yang relatif lebih besar dibandingkan perusahaan-perusahaan yang tidak terdaftar di BEI. Sebagian riset yang dilakukan terkait penghindaran yang dilakukan antar perusahaan afiliasi. Selain itu, riset-riset kuantitatif berbasis data sekunder belum dapat memetakan secara langsung penghindaran pajak yang dilakukan ada pada akun atau pos apa saja dalam laporan keuangan.

Sebagian riset kualitatif membahas celah pada ketentuan pajak yang berpotensi memunculkan penghindaran pajak. Untuk riset-riset berbasis studi kasus biasanya menggunakan satu atau beberapa perusahaan untuk dielaborasi sehingga dapat dipetakan kemungkinan adanya penghindaran pajak. Sedangkan, bagi peneliti yang menggunakan peraturan perundang-undangan, mengkaji kelemahan dari ketentuan dimaksud dari perspektif wajib pajak sehingga dapat diindentifikasi potensi penghindaran pajak.

Apabila dicermati dari karakteristik masing-masing riset baik kuantitatif maupun kualitatif maka keduanya diperlukan dalam mengenal, memahami, memetakan potensi dari penghindaran pajak. Untuk menganalisis kelemahan dari ketentuan perpajakan dapat dilakukan dengan metode kualitatif. Di sisi lain, metode kuantitatif memberikan sebuah informasi yang lebih umum dan terukur mengenai variabel apa saja yang memengaruhi penghindaran pajak. 
Hal ini sangat bermanfaat bagi otoritas pajak dalam melaksanakan post-audit. Dengan kata lain, kedua metode riset sangat penting dan bersifat komplementer.

\section{PENUTUP}

\section{Simpulan}

Penelitian ini berupaya mendapatkan jawaban mengenai riset dengan metode apa yang paling tepat untuk diaplikasikan di Indonesia dari kacamata otoritas pajak. Masing-masing metode memiliki kelebihan dan kelemahan, serta karakteristik yang unik. Di samping itu, untuk pelaksanaan riset penghindaran pajak di Indonesia pun memiliki beberapa keterbatasan khususnya untuk riset berbasis kuantitatif dengan data sekunder di mana data yang digunakan hanya data perusahaan-perusahaan yang terdaftar di BEI. Sedangkan untuk data-data perusahaan tertutup sulit untuk mendapatkannya dan kemungkinan pula sulit untuk dipublikasikan. Untuk itu riset di bidang kuantitatif dan kualitatif dapat saling melengkapi satu sama lain sehingga manfaat praktis dari riset dapat dioptimalkan.

Jika mengacu pada Pasal 18 UU PPh khususnya ayat (2) dan ayat (3) serta ayat (3b) maka bentuk penghindaran pajak secara spesifik mengacu pada transaksi dengan pihak berelasi, dan penyertaan modal di luar negeri. Sedangkan jika mengacu pada Pasal 16C UU PPN, penghindaran pajak terkait dengan pengenaan PPN bagi kegiatan membangun sendiri. Namun demikian, di luar pasal-pasal tersebut praktik penghindaran pajak dapat terjadi sesuai dengan strategi dan perencanaan pajak yang dilakukan.

\section{Saran}

Penelitian ini memiliki keterbatasan yaitu tidak memasukkan penelitian kuantitatif berbasis data primer. Selain itu, penelitian ini juga hanya menggunakan beberapa riset untuk dibandingkan dan dielaborasi. Untuk riset berikutnya, dapat dilakukan dengan pemetaan secara lebih komprehensif baik dari sisi kuantitas riset yang telah ada di Indonesia maupun paradigma analisis yang digunakan.

\section{DAFTAR PUSTAKA}

Addison, S., \& Mueller, F. (2016). The Dark Side of Profession: The Big Four and Tax Avoidance. Accounting, Auditing and Accountability Journal, 28(8), 1263-1290.

Addo, E. B., Salia, H., \& Nakyea, A. A.-. (2017). Transfer Pricing Abuse: the Ghanaian Perspective and the Role of the Accountant in Tax Compliance. International Journal of Accounting and Taxation, 5(2), 83-91. https://doi.org/10.15640/ijat.v5n2a6

Alm, J. (1988). Compliance Costs and The Tax Avoidance-Tax Evasion Decision. Public Finance Quarterly. 16(I), 31-66.

Álvarez-Martínez, M. T., Barrios, S., d'Andria, D., Gesualdo, M., Nicodeme, G., \& Pycroft, J. (2021). How large is the corporate tax base erosion and profit shifting? A general equilibrium approach. Economic Systems Research. https://doi.org/10.1080/09535314.2020.1865882

Amidu, M., Coffie, W., \& Acquah, P. (2019). Transfer pricing, earnings management and tax avoidance of firms in Ghana. Journal of Financial Crime, 26(1), 235-259. https://doi.org/10.1108/JFC-10-2017-0091

Arham, A., Firmansyah, A., Nor, A. M. E., \& Vito, B. (2020). Tax Aggressiveness Research in Indonesia: A Bibliographic Study. Talent Development \& Excellence, 12(2s), 1966-1986. http://www.iratde.com

Aryotama, P., \& Firmansyah, A. (2020a). The Association Between Related Party Transaction And Tax Avoidance In Indonesia. AFEBI Accounting Review, 4(02), 117. https://doi.org/10.47312/aar.v4i02.243

Aryotama, P., \& Firmansyah, A. (2020b). The effect of business strategy on tax avoidance in 
Indonesia's consumer goods industry. Public Sector Accountants and Quantum Leap: How Far We Can Survive in Industrial Revolution 4.0?, August, 235-239. https://doi.org/10.1201/9780367822965-48

Astrini S.F., Biekayanti, G., \& Suharjanto D. (2015). Praktik Corporate Governance dan Nilai Perusahaan BUMN di Indonesia. Jurnal Akuntansi, 19(1), 1-30 https://doi.org/10.24912/ja.v19i1.111

B.M, A. I., \& Wijaya, S. (2018). Analisis Upaya Wajib Pajak Melakukan Tax Avoidance Melalui Hibah. Jurnal Ilmiah Akuntansi Kesatuan, 5(2), 086-096. https://doi.org/10.37641/jiakes.v5i2.80

Bennedsen, M., \& Zeume, S. (2018). Corporate tax havens and transparency. Review of Financial Studies, 31(4), 1221-1264. https://doi.org/10.1093/rfs/hhx122

Bimo, I. D., Prasetyo, C. Y., \& Susilandari, C. A. (2019). The effect of internal control on tax avoidance: the case of Indonesia. Journal of Economics and Development, 21(2), 131143. https://doi.org/10.1108/JED-10-2019-0042

Cassell, C., \& Symon, G. (2004). Essential Guide to Qualitative Methods in Organizational Research.

Chen, S., Xu, L., \& Jebran, K. (2021). The effect of Confucian culture on corporate tax avoidance: evidence from China. Economic Research-Ekonomska Istrazivanja , 34(1), 1342-1365. https://doi.org/10.1080/1331677X.2020.1825105

Clausing, K. A., Saez, E., \& Zucman, G. (2020). Ending Corporate Tax Avoidance and Tax Competition: A Plan to Collect the Tax Deficit of Multinationals. SSRN Electronic Journal, January, 1-18. https://doi.org/10.2139/ssrn.3655850

degl'Innocenti, D. G., \& Rablen, M. D. (2017). Income Tax Avoidance and Evasion: A Narrow Bracketing Approach. Public Finance Review, 45(6), 815-837. https://doi.org/10.1177/1091142116676362

Desai, M. A., \& Dharmapala, D. (2006). Corporate tax avoidance and high-powered incentives. $\begin{array}{llll}\text { Journal of Financial } & \text { Economics, } & \text { 79(1), }\end{array}$ https://doi.org/https://doi.org/10.1016/j.jfineco.2005.02.002

Dwi Laksono, D. G., \& Firmansyah, A. (2020). the Role of Managerial Ability in Indonesia: Investment Opportunity Sets, Environmental Uncertainty, Tax Avoidance. Humanities \& Social Sciences Reviews, 8(4), 1305-1318. https://doi.org/10.18510/hssr.2020.84123

Dyreng, S. D., Hanlon, M., \& Maydew, E. L. (2008). Long-run corporate tax avoidance. Accounting Review, 83(1), 61-82. https://doi.org/10.2308/accr.2008.83.1.61

Falbo, T. D., \& Firmansyah, A. (2018). Thin Capitalization, Transfer Pricing Aggresiveness, Penghindaran Pajak. Indonesian Journal of Accounting and Governance, 2(1), 1-28. https://doi.org/10.36766/ijag.v2i1.6

Falbo, T. D., \& Firmansyah, A. (2021). Penghindaran Pajak Di Indonesia: Multinationality Dan Manajemen Laba. Bisnis-Net Jurnal Ekonomi Dan Bisnis, 4(1), 94-110. https://doi.org/10.46576/bn.v4i1.1325

Ferdiawan, Y., \& Firmansyah, A. (2017). Pengaruh Political Connection, Foreign Activity, Dan, Real Earnings Management Terhadap Tax Avoidance. Jurnal Riset Akuntansi Dan Keuangan, 5(3), 1601-1624. https://doi.org/10.17509/jrak.v5i3.9223

Finér, L., \& Ylönen, M. (2017). Tax-driven wealth chains: A multiple case study of tax avoidance in the finnish mining sector. Critical Perspectives on Accounting, 48, 53-81. https://doi.org/10.1016/j.cpa.2017.01.002

Firmansyah, A., \& Febriyanto, A. S. (2018). The Effects of Tax Avoidance, Accrual Earnings Management, Real Earnings Management, and Capital Intensity on the Cost of Equity. Jurnal Dinamika Akuntansi, 10(1), 40-50. https://doi.org/10.15294/jda.v10i1.12976

Firmansyah, A., \& Triastie, G. A. (2020). The role of corporate governance in emerging market: 
Tax avoidance, corporate social responsibility disclosures, risk disclosures, and investment efficiency. Journal of Governance and Regulation, 9(3), 8-26. https://doi.org/10.22495/jgrv9i3art1

Graham, J. R., Hanlon, M., Shevlin, T., \& Shroff, N. (2014). Incentives for Tax Planning and Avoidance: Evidence from the field. Accounting Review, 89(3), 991-1023. https://doi.org/https://doi.org/10.2308/accr-50678

Granda, M. L. (2021). Tax haven ownership and business groups: Tax avoidance incentives in Ecuadorian firms. Journal of Business Research, 130(July), 698-708. https://doi.org/10.1016/j.jbusres.2020.07.012

Guenther, D. A., Matsunaga, S. R., \& Williams, B. M. (2017). Is tax avoidance related to firm risk? Accounting Review, 92(1), 115-136. https://doi.org/10.2308/accr-51408

Gunawan, A. (2022). Peranan Good Corporate Governance Dalam Meminimalisir Praktik Penghindaran Pajak Pada Perusahaan Go Publik. Owner: Riset \& Jurnal Akuntansi, 6, 379-385.

Hanlon, M., \& Heitzman, S. (2010). A review of tax research. Journal of Accounting and Economics, 50(2-3), 127-178. https://doi.org/10.1016/j.jacceco.2010.09.002

Hasan, M. M., Lobo, G. J., \& Qiu, B. (2021). Organizational capital, corporate tax avoidance, and firm value. Journal of Corporate Finance, 70(July). https://doi.org/10.1016/j.jcorpfin.2021.102050

Hasseldine, J., \& Morris, G. (2013). Corporate social responsibility and tax avoidance: A comment and reflection. Accounting Forum, 37(1), 1-14. https://doi.org/10.1016/j.accfor.2012.05.001

Hidayat, H., \& Wijaya, S. (2021). Pengaruh Manajemen Laba, Profitabilitas Dan Transfer Pricing Terhadap Penghindaran Pajak. Bina Ekonomi, 25(2), 61-79.

Irawan, F. (2020). Does Firms' Life Cycle Influence Tax Avoidance? Evidence from Indonesia. International Journal of Innovation, Creativity and Change. 14(1), 1211-1229.

Irawan, F., Kinanti, A., \& Suhendra, M. (2020). The Impact of Transfer Pricing and Earning Management on Tax Avoidance. Talent Development \& Excellence, 12(September), 3203-3216.

http://search.ebscohost.com/login.aspx?direct $=$ true $\& d b=s 3 h \& A N=144289767 \&$ lang $=j$ a\&site = ehost-live

Irawan, F., \& Turwanto. (2020). The Effect of Tax Avoidance on Firm Value with Tax Risk as Moderating Variable. Test Engineering and Management, 83(May), 9697-9707.

Irawan, F., \& Utama, A. S. (2021). The Impact of Tax Audit and Corruption Perception on Tax Evasion. Journal of Business and Society, 22(3), 1158-1173.

Juniawaty, R. (2018). Tax Planning PPh Pasal 21 sebagai Upaya Efisiensi Pajak Perusahaan. Sosio E-Kons, 10(3), 234. https://doi.org/10.30998/sosioekons.v10i3.2843

Lee, J. Y. (2019). The Effect of Tax Avoidance on Firm Risk. Korean Corporation Management Review, 26(2), 55-78. https://doi.org/10.21052/kcmr.2019.26.2.03

Lejour, A. M. (2021). The Role of Conduit Countries and Tax Havens in Corporate Tax Avoidance. SSRN Electronic Journal. https://doi.org/10.2139/ssrn.3843734

Meier, J.-M., \& Smith, J. (2020). Tax Avoidance through Cross-Border Mergers and Acquisitions. SSRN Electronic Journal. https://doi.org/10.2139/ssrn.3639640

Nakano, D., \& Muniz, J. (2018). Writing the literature review for empirical papers. Production, 28. https://doi.org/10.1590/0103-6513.20170086

Nugroho, A., Rinaldi, Y., \& Efendi, E. (2020). Tanggung Jawab Pejabat Pembuat Akta TAnah dalam Pembuatan Akta untuk Menghindari Pajak. Diversi Jurnal Hukum Indonesia, 6(April), 73-91.

Nurhandono, F., \& Firmansyah, A. (2017). Pengaruh Lindung Nilai, Financial Leverage, Dan 
Manajemen Laba Terhadap Agresivitas Pajak. Media Riset Akuntansi, Auditing \& Informasi, 17(1), 31. https://doi.org/10.25105/mraai.v17i1.2039

Prastiwi, D., \& Ratnasari, R. (2019). The Influence of Thin Capitalization and The Executives' Characteristics Toward Tax Avoidance by Manufacturers Registered on ISE in 2011-2015. AKRUAL: Jurnal Akuntansi, 10(2), 119. https://doi.org/10.26740/jaj.v10n2.p119-134

Preuss, L. (2010). Tax avoidance and corporate social responsibility: You can't do both, or can you? Corporate Governance, 10(4), 365-374. https://doi.org/10.1108/14720701011069605

Rabbi, F., \& Almutairi, S. S. (2021). Corporate Tax Avoidance Practices of Multinationals and Country Responses to Improve Quality of Compliance. International Journal for Quality Research, 15(1), 21-44. https://doi.org/10.24874/IJQR15.01-02

Sebele-Mpofu, F., Mashiri, E., \& Schwartz, S. C. (2021). An exposition of transfer pricing motives, strategies and their implementation in tax avoidance by MNEs in developing countries. Cogent Business and Management, $8(1)$. https://doi.org/10.1080/23311975.2021.1944007

Sikka, P. (2015). No Accounting for Tax Avoidance. Political Quarterly, 86(3), 427-433. https://doi.org/10.1111/1467-923X.12175

Slemrod, J., \& Yitzhaki, S. (2002). Tax Avoidance, Evasion, And Administration. Handbooks in Economics, 3, 1423-1470. https://doi.org/10.1016/S1573-4420(02)80026-X

Stiglitz, J. E. (1985). The Genaral Theory of Tax Avoidance. National Tax Journal, 38(1868), 325-337.

Taylor, G., Richardson, G., \& Taplin, R. (2015). Determinants of tax haven utilization: Evidence from Australian firms. Accounting and Finance, 55(2), 545-574. https://doi.org/10.1111/acfi.12064

Utami, M. F., \& Irawan, F. (2022). Pengaruh Thin Capitalization dan Transfer Pricing Aggressiveness terhadap Penghindaran Pajak dengan Financial Constraints sebagai Variabel Moderasi. Owner: Riset \& Jurnal Akuntansi. 6(1), 386-399.

Wang, F., Xu, S., Sun, J., \& Cullinan, C. P. (2020). Corporate Tax Avoidance: a Literature Review and Research Agenda. Journal of Economic Surveys, 34(4), 793-811. https://doi.org/10.1111/joes.12347

Wijaya, S., \& Arumningtias, D. (2021). Preventing The Potentialtaxavoidancein Government Regulation Of The Republic Of Indonesia Number 23 Of 2018. Multicultural Education, 7(1), 28-8. https://doi.org/10.5281/zenodo.4515858

Wijaya, S., \& Rahayu, F. D. (2021). Pengaruh Agresivitas Transfer Pricing, Penggunaan Negara Lindung Pajak, Dan Kepemilikan Institusional Terhadap Penghindaran Pajak. Jurnal Informasi, Perpajakan, Akuntansi, Dan Keuangan Publik, 16(2), 245. https://doi.org/10.25105/jipak.v16i2.9257

Wijaya, S., \& Setiawan, A. (2021). Potensi Tax Avoidance Terhadap Peraturan Pemerintah Nomor 23 Tahun 2018 Oleh Wajib Pajak Perseroan Terbatas. Owner, 5(2), 407-416. https://doi.org/10.33395/owner.v5i2.490

Winata, F. (2014). Pengaruh Corporate Governance Terhadap Tax Avoidance Pada Perusahaan Yang Terdaftar Di Bursa Efek Indonesia Tahun 2013. Tax \& Accounting Review, 4 (1)(1), $1-11$. 